$\operatorname{sinf}-741075--4$

UCRL-JC-116436

PREPRINT

\title{
Groundwater Flux, Travel Time, and Radionuclide Transport
}

\author{
Dwayne A. Cnesnut
}

This paper was prepared for submittal to the

18th International Symposium on the Scientific Basis for

Nuclear Waste Management

October 23-27, 1994

Kyoto, Japan

August 1994

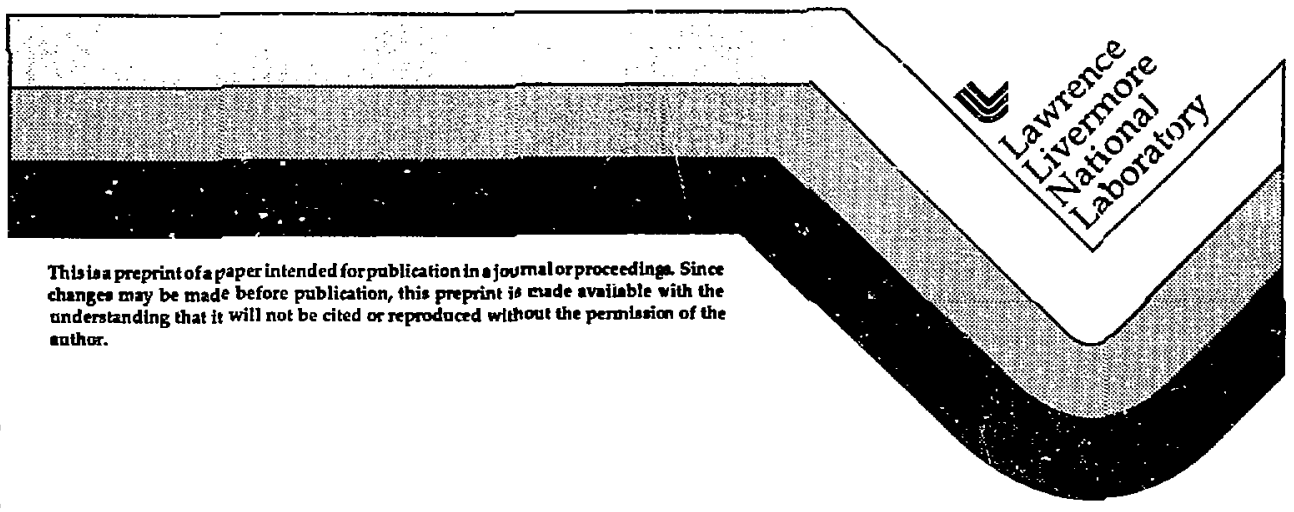

This ian preprint of a paper intended for poblieation in a joumalor proceedinge Since changes my be made before pablieation, this preprint is eade aviibble with the anderstanding that it will not be cited or reproduced without the permiasion of the enthor. 


\section{DISCLAIMER}

Thta docement was prepared as an eroond of wort ppotrored by $m$ ageng of the United States Govemment. Neither the United Stele Governewtent nor the Uni verzily

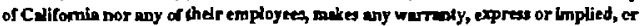
essumes any legelliability or repoosibility forthe ecarecy, completepess, or wesulness of any information, apparil os, prodpct, or prucess disdowed, or represents that its use

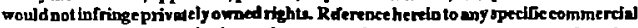
produts, procese, orserfice by trade nane, trademark, manfecturer, or otherwise,

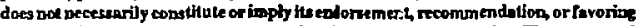
by the United States Government of the University of Callfornis. The views and

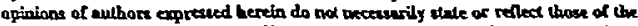
United States Governmert or the Universily of Celfforries and thall not be used for odvertising or product epdorsewent parpout. 


\section{DWAYNE A. CHESNUT}

Lawrence Livermore National Laboratory, P.O. Box 808, L-206, Livermore, CA 94550

\section{ABSTRACT}

Inflow measurements at Stripa and in other underground openings in Sweden, as well as observations elsewhere in mines and tunnels, reveal that there is generally an extremely broad distribution of groundwater flux in fractured rock. Non-sorbing and sorbing tracer tests typically show similar variability in groundwater travel time (GWTT) and tracer transport.

In the U.S. Nuclear Waste Program, Nuclear Regulatory Commission regulations require the GWTT from the disturbed zone to the accessible environment to exceed 1000 years. The regulations seem to envision a rather uniform and narrow distribution of travel time, witi perhaps a few identifiable "fast pathways" contained within the rock mass surrounding a potential repository. The premise is that most of these features could be mapped during site cl-_acterization, and that regions of the potential repository host rock containing such features could be avoided during waste emplacement.

However, both field experience and theoretical studies in recent years provide strong evidence that groundwater \$lux, GWTT, and aqueous transport of dissolved substances exhibit extremely heterogeneous behavior, even in intact porous media and in fractured rock regions between major features. These phenomena are all dominated by the spatial distribution of permeability within the rock mass of interest. The permeability distribution is often approximately log-normal, with a natural log standard deviation, $\sigma$. For unfractured porous rock, $\sigma$ typically ranges from about 0.6 to about 1.2 for field-scale investigations, and for fractured permcable media, it frequently exceeds 2. Values of $\sigma$ smaller than 0.6 may be observed in small field-scale projects when the macroscopic flow regime is essentially linear within very uniform sediments and in laboratory displacement experitments.

With some additional assumptions, a log-normal permeability distribution implies that groundwater flux, GWTT, and the transport of radionuclides from a potential repository are also log-normal. To first order, the appropriate value of $\sigma$ describing these distributions is the same as the value for the permeability distribution. This allows $\sigma$ to be estinated from a large number of hydraulic or pneumatic packer tests within the fractured rock mass of interest.

We define a groundwater transport function (GWTF) for the rate of radioactivity release to the accessible environment (AF) at time $t$ resulting from the release of a pulse of unit activity at time 0 . The GWTF depends on the mean groundwater travel time, $t_{w}$, and $\sigma$, as well as the retardation factor and decay constant. As $\sigma$ increases from 0 (a hypothetical completely homogeneous system), the radioactivity breakthrough at early time increases from 0 to $100 \%$. This behavior is consistent with our intuitive notions of "fast transport pathways" in heterogeneous systems, and $\sigma$ is thus seen to be a parameter for quantifying the effects of heterogeneity.

Convolution of the GWTF with a time-dependent release function for the Engineered Barier System (EBS) is easily performed numerically, resulting in the rate of release to the AE as a function of time, which can then be integrated numerically to calculate the cumulative release as a function of time. The convolution approach cleaty separates the effects of uncertainty and heterogeneity on repository performance and is extremely useful for sensitivity analyses. An example calculation shows the combinations of $\sigma$ and $t_{w}$ required for compliance with total system release standards. 
Since the effect of heterogeneity is captured by a single parameter in a deterministic calculation, uncertainty can be investigated separately by Monte Carlo sampling from distribution: of such parameters as $\sigma, t_{w}$, and source term strength, allowing (in the future) specific and scientifically meaningful goals to be defined for both site characterization and design.

Finally, we emphasize that this approach, in its present form, does not include thermal effects. These effects may dominate both the EBS failure rate and hydrogeochemical behavior, including radionuclide transport, for most of the compliance period and beyond. It cannot be used directly to support ary particular thermal loading straiegy.

\section{INTRODUCTION}

Lawrence Livermore National Laboratory (LLNL) provides the scientific and engineering bases for design and performance analyses of the waste package and other components of the engineered barrier system (EBS) for a potential repository at Yucca Mountain, Nevada. The EBS is an important component of a multi-barrier system designed to isolate radioactive waste until it decays to the point that it is no longer radiologically hazardous to humans or other species. Its performance depends strongly upon the amount, chemical composition, and temperature of liquid water in the "near field" region immediately surrounding the waste packages.

For this reason, much of LLNL's Yucca Mountain research has been directed toward understanding flow, transport, and chemical processes in fractured rock under both preemplacement and post-emplacement conditions. Because the radioactive decay heat from a potential repository at Yucca Mountain would dominate the movement of water for thousands of years within the entire repository block and possibly aven beyond, the spatial domain of our investigations ranges from the scale of individual fracture apertures (micrometers) to a few kilcmeters.

This work, combined with our research in connection with the Äspö Hard Rock Laboratory in Sweden, has resulted in the development of a promising bounding calculation for radionuclide transport from the EBS to the AE. At present, these bounding calculations do not include the effects of decay heat on repository performance. They do appear promising for providing reasonable assurance that total system performance could meet regulatory requirements under ambient condtions, even given available evidence that the system is highly heterogeneous. The thermal loading decision then becomes largely a matier of demonstrating which, if any, thermal loads make it possible to meet or exceed the EBS subsystem requirements.

\section{GROUNDWATER FLUX}

The most striking feature of groundwater flow through fractured rock is its extreme variability, as illustrated by the experiment of Neretnieks, Abelin, and Birgersson (1) in the International Stripa Project.

Water flow rates were measured for about three years into 375 one-meter by two-meter rectangles covered by plastic sheets along the top and sides of a drift. The wettest rectangle accounted for about $10 \%$ of the total flow, $50 \%$ of the total flow came from $3 \%$ of the area, and 230 of the rectangles (about $\mathbf{7 0 \%}$ ) had no rneasurable flow. We speculate that any fractured rock mass would exhibit a qualitatively similar variability in flow rate, even under the partially saturated conditions at Yucca Mountain, Nevada.

Chesnut (2) showed that the Stripa flow rate cumulative fequency distribution was lognormal, if only the rectangles with measurable inflow rates were used in the calculation, and proposed that the foilowing equations might represent a general description for the spatial distribution of flux into an underground opening ( $u_{w}$ is the groundwater flux): 


$$
\begin{aligned}
& \mathrm{P}\left[u_{w}=0\right]=\varepsilon \\
& \mathrm{P}\left[0<u_{w} \leq u\right]=(1-\varepsilon) \cdot \Phi\left\{\frac{\ln (u /(u))+\sigma^{2} / 2}{\sigma}\right\}
\end{aligned}
$$

If a plane were passed through a fractured rock mass, a fraction $\varepsilon$ of the area would encounter no water flow, and a fraction 1-E would have a continuous distribution of flux, which can be approximated by a log-normal distribution ( $\boldsymbol{\Phi}$ denotes the normal probability integral). In this mathematical model, the fux distribution is completely determined by specifying 3 parameters: $\varepsilon, \sigma$, and the average $f u x,\langle u\rangle$. For Stripa, $\varepsilon$ is about 0.7 , and $\sigma$ is about 1.6

\section{GROUNDWATER TRAVEL TIME}

For any real system, there will be a distribution of groundwater travel time, not a single value. This distribution can be determined by measuring the breakthrough concentration of a nonsorbing tracer as a function of time. Breakthrough curves are simplest to interpret when the inlet concentration is either

1. A step function, i.e., the concentration is increased from 0 to $C_{0}$ at time 0 and then held constant. The breakthrough curve starts at 0 for $t=0$ and approaches 1.0 as $t \rightarrow \infty$, as illustrated schematically in Fig. 1. This is the cumulative distribution function for the groundwater travel time.

2. A very narrow pulse, in which a known mass of tracer is injected at constant concentration $C_{0}$ for a shor time, $\delta$. The breakthrough curve again starts at 0 for $t=0$, but approaches 0 as $t$ tends to infinity. This is the density function for the groundwater travel time (see Fig. 2).

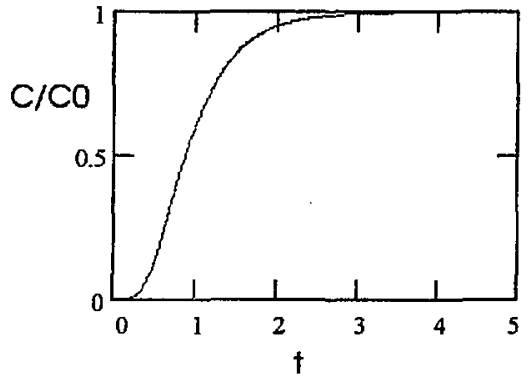

Figurel. Breakthrough curve for continuous injection of a non-sorbing tracer.

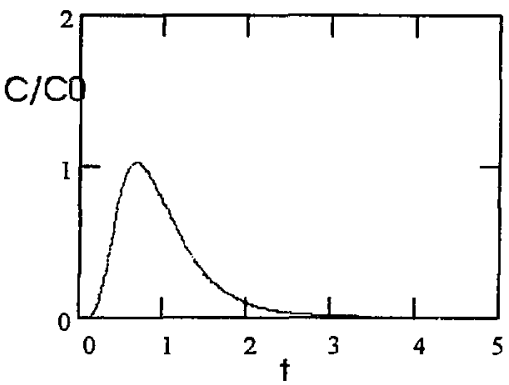

Figure 2. Breaktiurcugh curve for pulse injection of a non-sorbing tracer.

In spite of the probabilistic terminology, these are deterministic functions for a given flow system, assuming that the spatial distributions of porosity and permeability are fixed and that the boundary conditions do not change during the experiment. The function shown in Fig. 2 is an example of the GWTF for a non-sorbing tracer (or radionuclide). The pulse breakthrough curve for a sorbing species defines the groundwater transport function for that species. In general, the more heterogeneous the flow system, the broader will be its GWTF.

Three mechanisms cause the "smearing out" of a step-function concentration front, or the equivalent broadening of a pulse, as traced fluid moves from the inlet to the outlet of the system. 
The most familiar is classical dispersion, for which Hewett (3) has suggested the term gradient dispersion, because the mixing of two fluids is assumed to be proportional to local concentration gradients within the porous medium.

A second mecharism occurs in two- or three-dimensional flow between distinct sources and sinks in homogeneous media. In uniform porous media, a flow field can be described by constnucting a network of constant head contours and orthogonal, intersecting streamlines. Streamlines represent the flow paths from sources to sinks, and there is no mixing of fluids between adjacent streamlines. Uniess they are all exactly the same length and eveniy spaced, which occurs only in a perfectly linear flow system, the travel time will be different from one streamline to another, resulting in a breakthrough curve which is more diffuse than the input distribution.

The third mechanism is channel flow, of which streamlines may be regarded as a special case. In the limit of independent, non-interacting channels, fluids do not mix between the inlet and outlet of the system. One example of channel flow is a perfectly stratified medium, in which there is no crossflow between layers. This conceptual model was first used by Stiles (4) and by Dykstra and Parsons (5) for predicting the waterflood response of oil reservoirs with discrete independent strata having a log-normal permeability distribution. The parameter $\sigma$ of the log-normal distribution was replaced in the latter analysis by the Dykstra-Parsons coefficient, $V_{D P}$, which is still used in petroleum engineering as a measure of heterogeneity:

$$
\sigma=-\ln \left(1-V_{D P}\right)
$$

Chesnut and others (7) extended this model to the case of a continuous log-normal permeability listribution for both waterflooding and surfactant flooding, resulting in simple analytic expressions for oil and water production as functions of time.

Two- and three-dimensional networks of channels have been used by Neretnieks and others (6) in Sweden to model flow and transport in fractured granitic rock, in part because field observations indicate that only a small fraction of observed fractures actually contribute to flow and that only a small part of the observed trace length of a flowing fracture actually conducts fluid.

In either case (complete stratification or channeling), the apparent "dispersion" in outlet concentration arises from a non-uniform distribution of velocities between the sources and sinks. Hence, Hewett (3) considers these examples of velocity dispersion, and notes that there is no mixing within the medium and, therefore, no relationship of concentrations to local gradients.

The most important distinction between gradient (or Fickian) dispersion and velocity dispersion lies in the way the width of a pulse grows with distance. If the displacement obeys Fick's law, then the mixing zone width increases as the square root of the mean distance traveled, and the dispersivity will be a constant. For velocity dispersion, the apparent mixing zone width increases in proportion to some other power (greater thar 0.5 ) of the distance traveled. In the limit of a continuous log-normal distribution of independent permeable channels or strata, Chesnut (z) showed that the apparent mixing zone width grows as the first power of the mean distance traveled and that the apparent dispersivity increases linearly with distance, in reasonabls agreement with field-scale transport data.

\section{LOG-NORMAL TRANSPORT FUNCTIONS}

The dimensionless breakthrough curve for continuous injection of a tracer (or other dissolved species) was given in Chesnut (8) as: 


$$
\xi_{\gamma}(\tau)=\boldsymbol{\Phi}\left\{\frac{\ln (\tau)+\sigma^{2} / 2}{\sigma}\right\}
$$

Here, $\xi$ is the observed concentration, $C$, normalized by dividing by the injected concentration, $C_{0}$. The dimensionless time $\tau$ is just the actual time divided by a mean residence time, $t_{m}$, which is the same as the GWTT, $t_{w}$, for a non-sorbing species. The mean residence time is equal to $R_{F} t_{w}$ for a sorbing species, where $R_{F}$ is the retardation factor. The GWTF is just the derivative of Eq. (3):

$$
f_{w}(\tau, \sigma)=\frac{1}{\sqrt{2 \cdot \pi} \cdot \tau \cdot \sigma} e^{-\frac{1}{2}\left[\frac{\ln (\tau)+\sigma^{3} / 2}{\sigma}\right]^{2}}
$$

where

$$
\tau=\frac{t}{R_{F} \cdot t_{w}}
$$

For small values of $\sigma$, the GWTF defined by Eq. (4) has a symmetric peak near $\tau=1$, as shown in Fig. 3. As $\sigma$ increases, the curve at first flattens and develops a right-hand tail, while the peak moves to the left. As $\sigma$ increases further, the peak again becomes sharp and its location approaches the origin of the dimensionless time axis.

In other words, the GWTF approaches a delta function at $\tau=1$ as $\sigma$ tends to 0 , and a delta function at $\tau=0$ as $\sigma$ tends to infinity. The first limit corresponds to a system for which all groundwater travel time values are equal to the mean, producing the maximum possible radionuclide retardation. The second corresponds to a travel time of 0 , and the system is so heterogeneous that the geologic barrier would be totally ineffective in containing radionuclides.

\section{RADIONUCLIDE TRANSPORT}

For a radionuclide with decay constant $\alpha$, the radioactivity (neglecting daughters) ariving at the outflow boundary of the system at time $t$ after injecting an infinitesimal pulse at time 0 is given by a simple

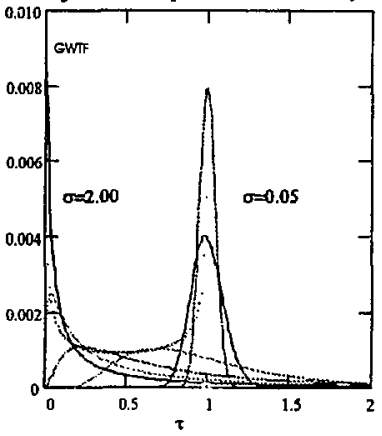

Figure 3. Pulse breakithrough curves for several values of $\sigma$, ranging from 0.05 for the sharp right-ihand peak to 2.0 for the sharp left-hand peak. modification of Eq. (4):

$$
f_{w}\left(t, t_{w}, R_{F}, \sigma, \alpha\right)=\frac{R_{F} \cdot t_{w}}{\sqrt{2 \cdot \pi \cdot t \cdot \sigma}} e^{-\frac{1}{2}\left[\frac{\ln \left(t / R_{F} \cdot t_{W}\right)+\sigma^{2} / 2}{\sigma}\right]^{2}} e^{-\alpha \cdot t}
$$

In Eq. (6), the dimensionless time has been replaced by its definition, $i / R_{F} t_{w}$, in order to show the explicit dependence of the pulse breakthrough curve on the mean groundwater travel time, $t_{\text {w' }}$ 
and the retardation factor, $R_{F}$. Note, however, that only the product appears, which implies that only the mean residence time of a species can be inferred from a breakthrough curve.

Assuming that the transport of radionuclides from the EBS to the AE can be bounded by the fiuction defined in Eq. (6), a bound on the rate of radioactivity release to the AE can be obtained by its convolution with the rate of mass release from the EBS:

$$
m_{A S}(t)=\int_{a}^{t} m_{E B S}(u) f_{w}\left(t-u, t_{w}, R_{F}, \alpha\right) d u
$$

In the US nuclear waste program, the EBS subsystem is required by NRC regulations [\$10 CFR 60] to provide "substantially complete containment" for 300 to 1000 years after waste emplacement, and, thereafer, to limit annual releases to not more than 1 part in $10^{5}$ of the inventory remaining at the end of the complete containment period. The hydrogeologic subsystem is required to provide a groundwater travel time of at least 1000 years from the repository disturbed zone to the $\mathrm{AE}$, evaluated under pre-emplacement conditions.

The technicai relevance of these subsystem requirements to overall system performance has not been clear. Even in simplified perfornance assessment caiculations, the EBS release function, or source term, is usually a relacively complex function of time, accounting for some details of solubility of the waste form, differential release rates of different radionuclides, and so on, making it difficult to clearly see the influence of bounding values. Domenico et al. (9) addressed this issue by considering a hypothetical reference repository which was assumed to exactly meet the EBS subsystem requirements, and then examining what would be needed from the hydrogeology in order to meet the total system requirement on cumulative radioactivity released in 10000 years (a probability of less than 0.1 that the "EPA Sum" could exceed 1.0 and less than $10^{-3}$ that it could exceed 10). In their deterministic calculation, they also assumed a GWT? of exactly 1000 years (although the efiect of classical dispersion was examined), and found that most radionuclides would be completely contained if their retardation factors were equal to $1 \mathrm{cr}$ greater. Most of the remaining radionuclides would require $R_{F}$ values greater than or equal to about 8.9, in the absence of dispersion, to keep the EPA sum below 1. Probabilites were not assessed.

The performance changes dramatically if the log-normal transport model is used, especially for large values of $\sigma$. By assuming a step-function for each radionuclide which exactly complies with the EBS subsystem requirements (no release for a time $t_{c c}$ and release at a constant activity rate until time $t_{e}$, when the inventory is exhausted), then performing its convolution with the GWTF and summing the result over all radionuclides, the following expression can be obtained for the EPA sum:

$$
M_{A E}=\sum_{i}^{N} r_{j} \cdot \int_{0}^{10000} G_{j}(t) d t
$$

In Eq. (8), the function $\mathrm{G}_{j}(t)$ is the convolution of the EBS step-function release rate and the GWTF for the $j^{t h}$ radionuclide. It depends upon the EBS parameters $f_{I}$ and $t_{c c}$ (fractional release rate and time for complete containment), the groundwater system parameters $\boldsymbol{t}_{w}$ and $\sigma$, the radionuclide parameters $I_{0 j}, \alpha_{j}$, and $\dot{E}_{j}$ (respectively, the number of Curies at emplacement, the decay constant, and the EPA limit, in Curies, for the $j^{\text {th }}$ radionuclide); and upon the hydrogeochemical parameters, $R_{F j}$. The factor $\mathrm{r}_{j}$ normalizes the EBS release rate of the $j^{t h}$ radionuclide by its EPA limit. These two functions can be calculated from the following equations (subscripts for radionuclide species have been omitted for simplification): 


$$
\begin{gathered}
\mathrm{G}(t)=-\frac{1}{\sqrt{2 \cdot \pi}} \cdot \int_{L(t)}^{U(t)} \exp \left(-W^{2} / 2-\alpha \cdot R_{F} \cdot l_{w} \cdot e^{a \cdot m-\sigma^{1 / 2}}\right) d w \\
r=\frac{e^{-a \cdot t_{\alpha}}}{E} \cdot I_{D} \cdot f_{L}
\end{gathered}
$$

The limits $\mathrm{L}(\mathrm{t})$ and $\mathrm{U}(\mathrm{t})$ beth depend upon $t_{w}, t_{c}, \sigma$, and $R_{F}$. $\mathrm{L}(\mathrm{t})$ also depends upon $\alpha$ and $f_{I}$.

A Mathcad ${ }^{\circledR}$ spreadsheet was developed to perform calculations for a hypothetical reference repository having some of the characteristics of Yucca Mountain. The assumed radionuclide inventory was 50 year oid spent nuclzar fuel with a total of 7028 Curies per metric ton of initial heavy metal (at emplacement), as given by O'Connell (10), modified by leaving out species with half-lives less than 20 years. Retardation factors and EPA limits for the remaining 29 species were taken from a report by Barnard (11). Calculation time is about 25 seconds to evaluate $G(t)$ for 40 values of $t$ and 29 species, for a single set of values for the parameters. Fig. 4 gives some indication of the power of this approach. In these calculations, the complete containment period

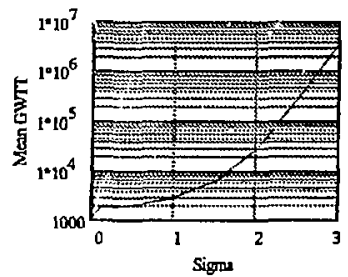

Figure 4. Values of $t_{w}$ and $\sigma$ giving an EPA sum of 1.0. is assumed fixed at 1000 years, and the controlied release fraction is $10^{-5}$ per year. Combinations of $t_{\mathrm{w}}$ and $\sigma$ lying below the curve shown in Fig. 4 would result in an EPA sum greater than 1.0; combinations lying above the curve would have a sum less than 1.0. Preliminary analyses (in progress) show that $\sigma$ for Yucca Mountain is very likely to be greater than 1.6, and could be greater than 2.2, based upon observations of bomb-pulse isotopes and reported well test data. As shown in Fig. 4, performance is extremely sensitive to $\sigma$ within this range, and a large mean GWTT is required to meet performance requirements.

Fabryka-Martin and others (12) reported apparent residence times of cosmogenic ${ }^{36} \mathrm{Cl}$ ranging from less than 50,000 y to $732,000 y$, with an average of 220,000 , in the Paintbrush non-welded tuff above the potential repository horizon. It appears likely that the convolution approach will demonstrate regulatory compliance if it can be shown that $\sigma$ is less than about 2.4 .

\section{CONCLUSION}

If all the inventory were released to the $A E$ at the time of emplacement, the EPA sum would be about 63,500 . Delaying this instantaneous release to 10,000 years would reduce this to about 4,300 . These values show the magnitude of reduction required from the total system. The convolution approach will allow a systematic mappitig of the relatively small parameter space defined by the $\log$-nomal model to determine regions of compliance. Since the effect of heterogeneity is captured by a single parameter in a deterministic calculation, the effects of uncertainty can be investigated separately by Monte Carlo sampling with assumed distributions for the parameters, allowing specific goals to be defined for both site characterization and design. Once ugain, we emphasize that this approach in its current form does not include the effects of thermal loading, which may dominate both the EBS failure rate and hydrogeochemical behavior for mosi of the compliance period and beyond. These effects remain to be bounded. 


\section{ACKNOWLEDGMENTS}

This work was perormed at Lawrence Livermore National Laboratory under the auspices of the US Department of Energy, contract number W-7405-ENG-48, and was sponsored jointly by the Yucca Mountain Site Characterization Project Office and the Interi :tional Programs Office of the Office of Civilian Radioactive Waste Management.

\section{REFERENCES}

1. I. Neretnieks, H. Abelin, and L. Birgersson, "Some Recent Observations of Channeling in Fractured Rocks - Its Potential Impact on Radionuclide Migration, "Proceedings, GEOVAL Conference, Stockholm, Sweden, April (1987).

2. D.A. Chesnut, "Characterizing the Altered Zone at Yucca Mountain: The Beginning of a Testing Strategy," Proceedings, Third International High-Level Radioactive Waste Management Conference; American Nucleer Society, Inc.: Las Vegas, NV, pp. 1026-1039 (1992).

3. T.A. Hewett, "Fractal Distributions of Reservoir Heterogeneity and Their Influence on Fluid Transport," SPE 6Ist Annual Technical Conference, New Orleans, LA, October 5-8, 1986, Preprint 15386, Society of Petroleum Engineers, Richardson, TX, (1986).

4. W.E. Stiles, "Use of Permeability Distributions in Water Flood Calculations, Transactions, A.I.M.E 186, pp. 9-13 (1949).

5. H. Dykstra and R.L Parsons, "The Prediction of Oil Recovery by Waterflooding," in Secondary Recovery of Oil in the United States, $2^{\text {nd }}$ ed., American Petroleum Institute, pp. 160-174 (1950).

6. I. Neretnieks, "A Note on Fracture Flow Dispersion Mechanisms in the Ground," Water Resources Resear:h 19, April, pp. 364-370, (1983).

7. D.A. Chesnut, D.O. Cox, and G. Lasaki, "A Practical Method for Waterflond Performance Prediction and Evaluation," Proceedings, Pan American Corsgress of Petroleum Engineering, Mexico City, Mar. 19-23 (1979).

8. D.A. Chesnut, "Dispersivity in Heterogeneous Permeable Media," Proceedings, Fifth Anmual International High-Level Radioactive Waste Management Conference, American Nuclear Society, Inc.: Las Vegas, NV, pp. 1822 - 1841 (1994).

9. P.A. Domenico, A. Lerman, and J.W. Bartlett, "The Disposal of Nuclear Waste: A Problem in Mass Maragement?," Ground Water 27, pp. 363 - 374 (1989),

10. W. O'Connell, T.S. Ueng, and L.C. Lewis, Post-Clasure Performance Assessment af Woste Packages for the Yucca Mountain Project, Lawrence Livermore National Laboratory National Laboratory, UCRL-ID-1 11979 , Livermore, CA (1993)

11. RW. Barnard, Review of Radionuclide Source Terms used for Performance-Assessment Analyses, Sandia National Laboratories, SAND92-2431, Albuquerque NM (1993).

12. J.T. Fabryka-Martin, S.J. Wightman, al al., "Distribution of Chlorine-36 in the Unsaturated Zone at Yucis Mountain: an Indicator of Fast Transport Paths," Proceedings, FOCUS '93 Conference on Site Characterization and Model Validation, Las Vegas, NV, Sep. 26-29, (1993). 